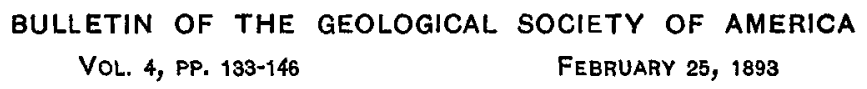

\title{
SOME ELEMENTS OF LAND SCULPTURE
}

BY LEWIS EZRA HICKS

(Offered to the Society for Publication August 15, 1892)

\section{CONTENTS}

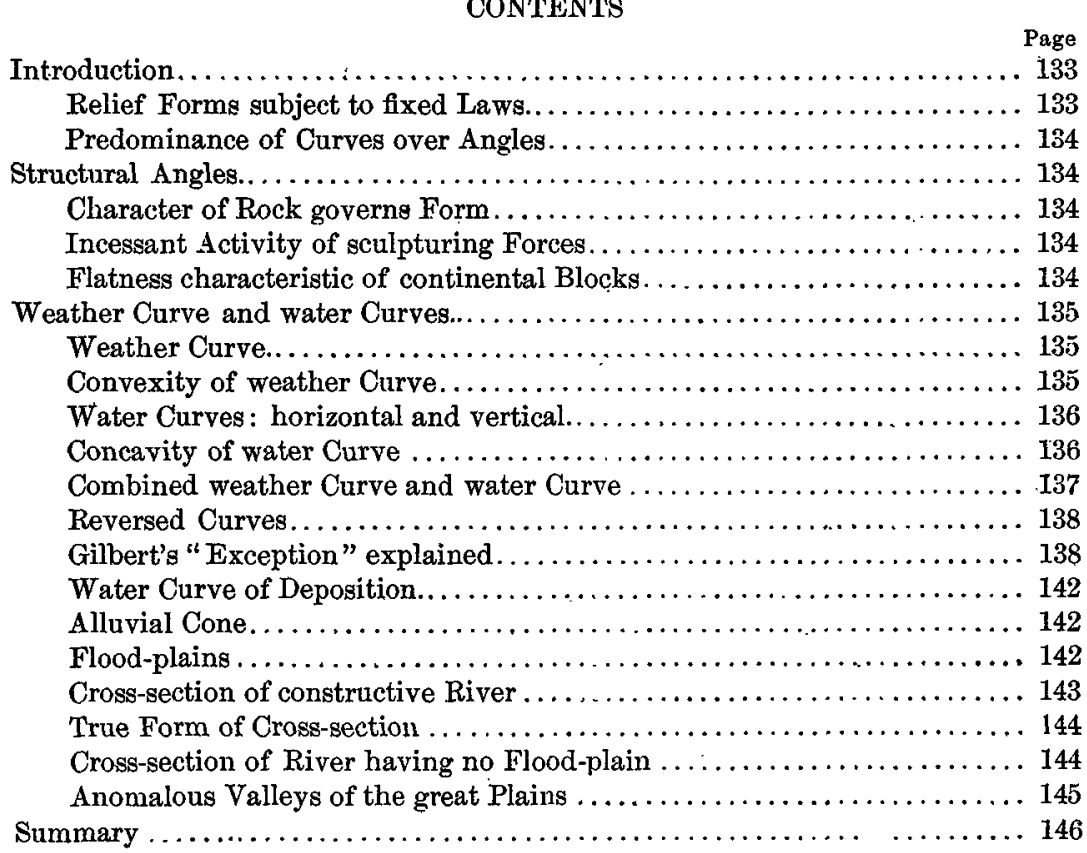

\section{INTRODUCTION.}

Relief Forms subject to fixed Laws.-Every element of form which gives character and expression to a landscape is determined by fixed laws. It is true that the arrangement of hills and vales does not conform to any simple geometric pattern. The sculpturing forces are complex, and the net result of their interaction is necessarily also complex and promis- 
cuous; still the action of each single force is regular, exact and unvarying, and the complex results are harmonious.

Predominance of Curves over Angles.-Most pleasing to the eye are those forms in a landscape which are bounded by curved lines and surfaces. Most striking, picturesque, rugged and impressive are those which are bounded by planes and angles. The former are far more common, and are produced by weathering and the washing of water. The latter depend upon the primitive structure of the rocks. Angular structural forms are the rough blocks which nature furnishes. Wind and frost, sun and rain, rills and rivers, are the tools which carve out of these rough blocks the beautiful landscapes which adorn the earth and make it a fit abode for man.

\section{Structural Angles.}

Character of Rock governs Form.-The laws of structure are intricate, and structural forms are infinite in variety. The planes may face in any direction, the angles may be acute or obtuse. That depends wholly upon the forces of upheaval and the laws of fracture in the different rocks; granite, limestone, basalt, conglomerate, each imparts a definite and characteristic expression to the landscape, because each breaks in a way peculiar to itself.

Incessant Activity of sculpturing Forces.-But with all this variety in detail there are certain broad, general features of structure which exert an important influence in the evolution of earth forms. The pent-up forces within the earth thrust up from time to time fresh blocks, to be disintegrated by the weather and carved by running water. These sculpturing forces never rest, while the forces of upheaval are intermittent. This incessant and universal activity of the sculpturing forces is the reason why the pleasing forms bounded by curves are more common than rough structural angles.

Flatness Characteristic of continental Blocks.-Though the internal forces are inconstant they are mighty. Mountains and continents are the burdens which they lift with ease. The lands are lifted and at the same time broken, faulted, bent and tilted this way and that. The resulting planes may slope north, south, east or west, and the pitch may be steep or gentle. Very steep structural planes are, however, of limited extent, while the great continental blocks must of necessity lie nearly flat, though the edges may be precipitous. Broad, flat blocks are therefore the usual raw materials for the sculpturing forces, and the resulting weather and water curves are dominated by these massive and nearly level. primitive elements of structure. Massive breadth and relatively slight inclination of the general surface are the fundamental character- 
istics of structure which prevail in the midst of the infinite variety of relief forms.

\section{Weather Curve and water Curves.}

Weather Curve.-The weathering of structural blocks reduces their salient angles, which are attacked from both of the adjacent faces at once. At the point $x$, figure 1 , the disintegrating forces act with twice as great intensity as at $b$, since the attack comes from two directions. The effects are more than twice as great at $x$, because the products of decay are quickly removed, exposing fresh surfaces to the attack, while at $b$ they remain to cover and protect the subjacent beds. Thus the structural block $m n o p$ is rounded off by weathering. The new outline $a b c$ is composite. The portion $d b e$ is a weather curve, convex upward. If weathering alone, without the aid of flowing water, has been concerned in the sculpturing process, the talus slopes $a d$ and $e . c$ will be structural planes, not curves. The structural angle $e c p$ will be determined by the

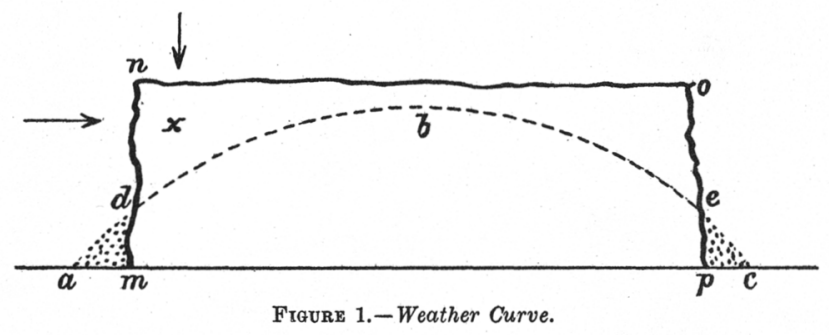

resting angle of the materials composing the talus, and that again will depend upon the size and form of the particles; but in humid regions the talus slopes will be quickly molded into water curves, as hereafter described. The resulting form $a b c$ will be a rounded rock, a smooth knob, or a round-topped hill or mountain, according as the original block was measured by inches or leagues.

Convexity of weather Curve. - The upward convexity of weather curves may be deduced also from the law that declivities vary directly as hardness. If we suppose the lowest beds composing a structural block to be very soft and the hardness to increase upward by regular gradations, a concave slope would result. Such a curve may actually be formed, but it would have to be ascribed to structure, not to weathering. Weather curves are often interrupted and modified by such structural accidents. But if the opposite conditions prevail-that is to say, if the soft bed is above and the hardness increases regularly downward-the law just enunciated will yield a slope of convex curvature. Now, whatever may 
be the primitive conditions of hardness in structural blocks, the tendency of weathering is to soften them from the top downward, or, in other words, to produce that set of conditions last supposed; hence the weather curve should be convex upward.*

Water Curves: horizontal and vertical. - The streams formed by the rains falling upon continental blocks have still greater sculpturing power than the weather. The rough edges are first scored down with ravines, as a carpenter hacks timber with an axe before he dresses it with finer tools. Some of the ravines lengthen into rivers and cut far back into the land. Except raw and fresh ravines, which may be tolerably straight, the path of flowing water is meandering. Graceful serpentine curves mark the flow-line, curves which constitute the most charming elements of scenery. These horizontal water curves address themselves to the eye in the most clear and agreeable manner; but there is another kind of water curve, the vertical, not always visible to the bodily eye, but none the less clear and real to the eye of the rnind. If we follow up a short

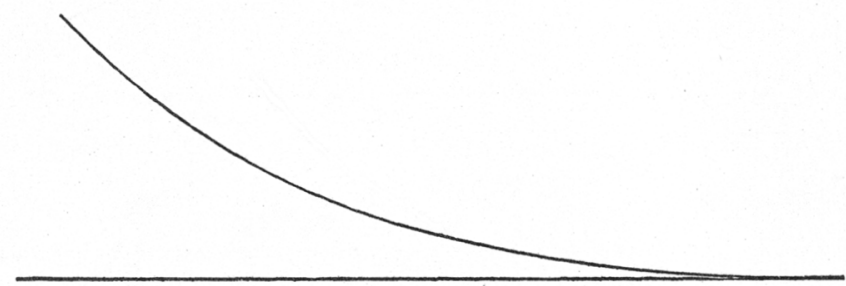

Figure 2.-Water Curve of Erosion.

ravine cut in homogeneous material we shall find a gentle slope at first, which gradually increases in steepness up to the crest of the escarpment. The positions of successive points of the channel, with their true relative distances above base-level, if drawn to scale, would form a curve like figure 2. This is the typical water curve of erosion.

Concavity of water Curve.-The water curve is precisely opposite to the weather curve, in that it is concave upward. In a short ravine it may be plainly seen, but the vertical curve of a river is so much flattened and extended that it can only be comprehended by the mind, not perceived by the eye. Indeed, there is a sense in which this vertical water curve, as defined by Gilbert, La Noë and Margarie and others, is not only imperceptible but purely ideal. It is seldom realized as a smooth curve, uniformly increasing its gradient upstream, except for short streams whose channels are cut in a homogeneous rock. The intervention of a harder stratum makes a jog in the curve. All cataracts and rapids with 
still water above them are in flat contradiction to the law of increasing gradient upstream and skyward concavity. Time enough being given, the obstruction would no doubt be cut through and the ideal curve established. All streams tend toward its realization as an ultimate goal. Cataracts are temporary departures from the rule, and quite evanescent when compared with the whole life history of a river.

Combined weather Curve and water Curve.-Another departure from the type is more permanent and universal, so frequent and lasting, indeed, that it almost deserves to be formulated as a distinct and opposite law. It is the fact that while the gradient increases upstream to a certain point and the curve is concave upward, as the definition requires, above that point the gradient diminishes, and the curve is convex upward, as at $a b$, figure 3. This is usually true of streams rising in extensive swamps and wet meadows. Even the mountain streams often flow sluggishly at first upon broad flat summits, then pitch headlong over the escarpment. We have seen above that breadth and flatness are the dominant elements of structure. The precipitous edges of broad continental

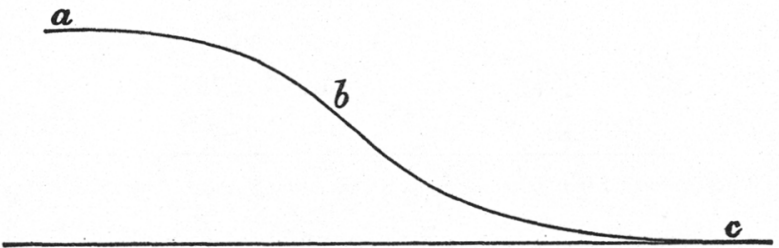

Figure 3.-Combined weather Curve $(a \cdot b)$ and water Curve $(b c)$.

blocks being rounded off impose their own curves upon the rivers. Thus the convex portion ( $a b$, figure 3 ) is not really a water curve. It is a temporary accommodation of a water gradient to the structural form upon which it flows. The true water curve ( $b c$, figure 3$)$ will moreover gradually encroach upon the upper convex curve $a b$, and, if the baseleveling be continued long enough, it will establish itself as a smooth concave curve from $c$ to $a$. Hence this exception, as in the case of cataracts, is an incident only of river history, the only differences being that it is more common and less transient; but, as I said above, it almost deserves to take rank as a distinct and coördinate law on account of its universality. The convex portion of the curve ( $a b$, figure 3$)$ is not, however, a new kind of curve, but one that has already been defined, viz, the weather curve. The double reversed curve ( $a b c$, figure 3 ) is the combination of the weather curve and the water curve of erosion. It is Hogarth's line of beauty, the most universal of earth forms. Almost every hill slope in a rolling country presents an upper convex portion 
(weather curve) and a lower concave portion (water curve). Some landscape engineers have caught nature's hint and give a terrace the form shown in figure 3, which is at once more elegant and more solid and durable than a slope in which the convexity is carried uniformly down

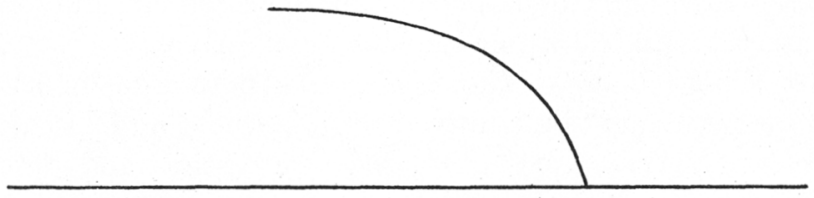

Figure 4.-Unstable artificial Curve.

to the base, as in figure 4 . The latter is unnatural and unstable, while the former is natural and stable.

Reversed Curves.-This combination of the weather curve with the vertical water curve of eresion when carried out upon both sides of a structural block (as $m n_{0} p$, figure 1 ), which is symmetrical and homogeneous, will give the pair of reversed curves shown in figure 5 , instead of the

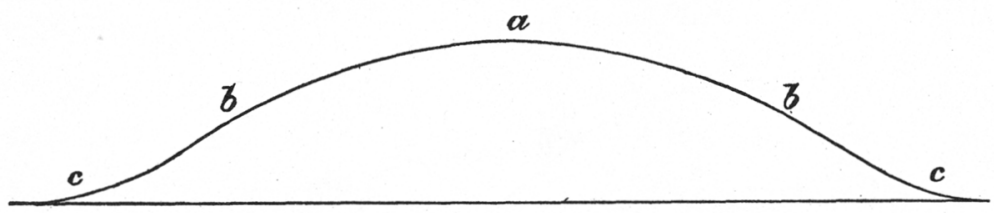

Figure 5.-Normal relief Form in an advanced Stage of Base-leveling.

simple convex weather curve $d b e$, figure 1 . Figure 5 is the normal pattern of relief forms in a region of advanced land sculpture. The summit $b a b$ is a simple, typical weather curve. The talus of figure 1 , with its clear-cut structural angle, $e c p$, has been replaced by the vertical water curve $b c$ (figure 5 ), which is concave upward.

Gilbert's "Exception" explained.-This same combination of weather and water curves is the true explanation of the "exception" noted by Gilbert,* who states :

"There is one other peculiarity $\dagger$ of bad-land forms which is of great significance, but which I shall nevertheless not undertake to explain. According to the law of

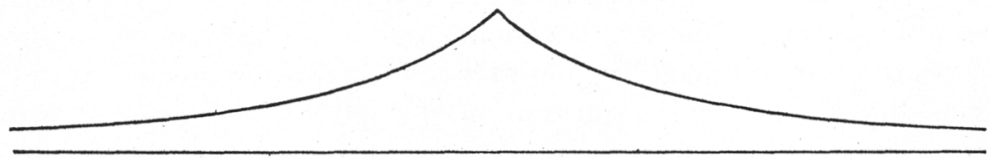

Figure 6.-Typical Profile of the drainage Slopes of Mountains.

* Report on the Geology of the Henry Mountains, pp. 122-123.

$\dagger$ Figure 6, which is a reproduction of Gilbert's figure 54 (ibid., p. 116), shows an angle. Such would be the actual result of intersecting water curves but for the effect of weathering, which rounds off the angle and replaces it by a curve convex upward. 
divides, as stated in a previous paragraph, the profile of any slope in the bad-lands should be concave upward, and the slope should be steepest at the divide. The union or intersection of two slopes on a divide should produce an angle [figure 6]. But in point of fact the slopes do not unite in an angle. They unite in a curve, and the profile of a drainage slope, instead of being concave all the way to its summit, changes its curvature and becomes convex. . . . From $a$ to $m$ [figure 7] and from $b$ to $n$ the slopes are concave, but from $m$ to $n$ there is a convex curvature. Where the flanking slopes are as steep as represented in the diagram, the convexity on the crest of a ridge has a breadth of only two or three yards, but where the flanking slopes are gentle, its breadth is several times as great. [Compare figure 5 with figure 7.] It is never absent.

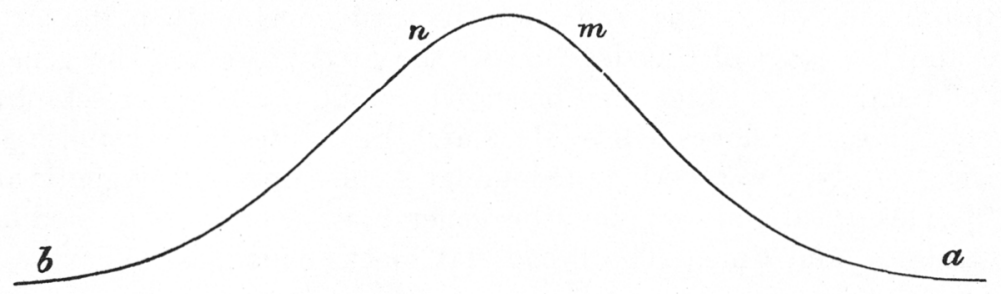

Figure 7.*-Cross-profile of bad-land Divide.

"Thus in the sculpture of the bad-lands there is revealed an exception to the law of divides, - an exception which cannot be referred to accidents of structure, and which is as persistent in its recurrence as are the features which conform to the law,-an exception which in some unexplained way is part of the law. Our analysis of the agencies and conditions of erosion, on the one hand, has led to the conclusion that (where structure does not prevent) the declivities of a continuous drainage slope increase as the quantities of water flowing over them decrease, and that they are great in proportion as they are near divides. Our observation, on the other hand, shows that the declivities increase as the quantities of water diminish, up to a certain point where the quantity is very small, and then decrease; and that declivities are great in proportion as they are near divides, unless they are very near divides. Evidently some factor has been overlooked in the analysis, - a factor which in the main is less important than the flow of water, but which asserts its existence at those points where the flow of water is exceedingly small, and is there supreme."

The missing factor is a simple and omnipresent one, namely, weathering. From $a$ to $m$ the water curve predominates, and its law of skyward concavity and increasing declivity is supreme. From $m$ to $n$ the weather curve predominates. As Gilbert remarks, "the flow of water is exceedingly small" there. It falls as rain and beats upon the crest, but that is a kind of weathering.

Besides supplying the missing factor which explains the puzzle and reconciles the results of scientific analysis with the facts as learned by

* Figure 7 is a reproduction of Gilbert's figure 60 , in his Report on the Geology of the Henry Mountains, p. 123. 
observation, I will add two observations suggested by the above quotation.

In the first place, the remark of Gilbert that "where the flanking slopes are as steep as represented in the diagram, the convexity on the crest of the ridge has a breadth of only two or three yards, but where the flanking slopes are gentle, its breadth is several times as great," conveys a partial truth, and at the same time suggests a broader truth. Gilbert merely affirms a relation between the steepness of the decivities and the breadth of the convex portion of the crest; but both of these correlated elements of form depend upon the relative intensities of water sculpture and weathering, and these in turn depend upon the structure and the stage of base-leveling in the given region. The general law of relative intensities may be stated as follows: If water sculpture predominates, the slopes will be steep and the divides narrow and high; and, conversely, if weathering predominates, the slopes will be gentle and the divides broad and low; but this general law is profoundly modified by structure and time. The broad, flat blocks which, as we have seen

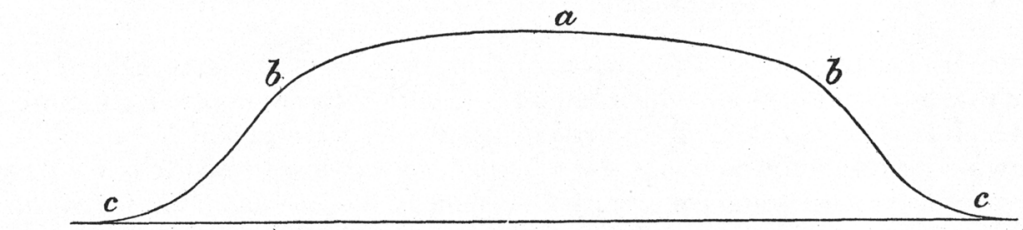

FigurE 8.-Illustrating the Co-existence of steep Slopes with broad weather Curves in an early Stage of Base-leveling.

$b, a b=$ weather curve; $b c=$ water curve.

above, are the normal types of raw material to be moulded by land sculpture, yield broad weather curves in the early stages of base-leveling wholly on account of their primitive structure. This is an exception to the general law, inasmuch as water sculpture is usually energetic in these early stages, and yet the weather curves are broad. It is also an exception to Gilbert's statement that the crest is narrow if the slopes are steep. Many cases occur in the earlier stages of base-leveling in which broad, flat weather curves are conjoined with very steep water curves, as in figure 8 . Many cases also occur in the same early stages of base-leveling in which the crest is narrow and the slopes steep, as affirmed by Gilbert and illustrated by his figure 60 . For example, the same mesa represented in cross-section by figure 8 would present many subordinate ridges between its lateral ravines with steep slopes and narrow crests. It is evident, therefore, that in this early stage of base-leveling, structure is the dominant factor whether the crest is narrow or broad. The steep water curves are the direct result of structure, since it is only by upheaval 
that such high gradients originate; and the broad crests are equally the direct effects of structure. The narrow crests exemplify the law of relative intensities, as stated above. Water sculpture is more energetic than weathering upon the precipitous edges of structural blocks; hence the slopes are steep and the crests narrow.

With the lapse of time the influence of structure gradually diminishes, and the stage which base-leveling has attained exerts the greater modifying influence upon the general law. In other words, time exerts a modifying influence in proportion to its quantity, measured from the beginning of the process of base-leveling. If this process has just begun, structure is supreme; but if it has reached its later stages the accumulated effects of time are supreme. Weathering and water sculpture both tend to become less energetic as the surface approaches base-level and the gradients flatten out, but the former retains a greater relative efficiency. The transportation and removal of the solid products of weathering does indeed steadily diminish, but solution-one form of weathering-and the transportation of its products goes on to the very last stages of land sculpture, after erosion has ceased. These last stages are therefore marked by water curves of slight declivity and weather curves of great breadth and flatness, both in fact closely approaching, but never quite reaching, an absolute base-level.

The general law with its modifications may be summed up thus: In early stages of base-leveling the predominance of water sculpture gives steep slopes and narrow crests, except where the latter have a breadth which is imposed upon them by the structure, and in late stages of baseleveling the predominance of weathering gives water curves of gentle declivity and broad, low weather curves.

The second observation suggested by the quotation from Gilbert is that the principles explained by him as applying to "bad-land forms" are equally applicable to all kinds and all stages of land sculpture. Bad lands constitute a certain striking phase of land sculpture, but they are nowise exceptional, so far as the general laws and processes of land sculpt ture are concerned. All of the factors are present and active. The resulis unique, not because of the absence of any familiar factor nor because of the presence of any new factor, but solely because of the relative intensity of the factors. Structure and water sculpture strongly predominate over weathering. Structural forces have supplied the cañon clays and marls as raw material-a matrix soft, homogeneous and peculiarly susceptible to rapid erosion on account of these properties and its considerable elevation. Water sculpture, attacking it with an energy proportional to its height above base-level and its lack of cohesion, cuts deep gashes so rapidly that weathering has little opportunity to round off the 
sharp edges. Indeed, this important factor occasionally seems, for the time being, to be wholly wanting. Forms like figure 9 are not uncommon in the bad lands. The summit $b b$ is protected with turf and the water curves $b c$ extend to the very crest without a trace of a weather curve; but the elimination of this factor is transitory. Visit the same butte some years later and you will find, if water sculpture is still vigorous, that the two water curves have so nearly joined that the turf has disappeared and a short weather curve occupies the narrow crest, as in figure 7 (Gilbert's figure 60), or, if water sculpture has been dormant, the angles $b b$ are replaced by weather curves. In a bad-land region all stages of the process may be observed, from the level-topped sharp-angled butte, often receiving the significant name "Box butte " or "Trunk butte," shown in figure 9 , to low domes like figure 5 , which are not bad-land forms at all. The same laws, the same processes are concerned in all these varied results, and a philosophic view of the subject demands that

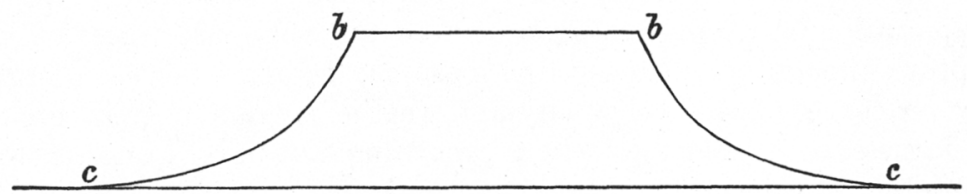

Figure 9.-Miniature Butte in the Bad Lands.

all phases and stages of land sculpture be grouped comprehensively instead of singling out a particular phase, though that may be a striking one.

Water Curve of Deposition.-The water curve of erosion, having its skyward face concave, is not the only vertical water curve. There is also the curve of deposition, which is convex upward. Where a mountain torrent debouches upon the plain, the débris carried or rolled along by it spreads out in a mass which is fan-shaped in ground plan and conical in elevation.

Alluvial Cone.-Such a deposit is usually called an alluvial cone, but, in view of its radial extension from the mouth of the gorge, Hilgard calls it a débris fan. The cross-section presents a typical water curve of deposition, convex upward.

Flood-plains.-The flood plains of rivers, so far as they are built up by sediment spreading laterally from the channel during floods, $*$ follow the

\footnotetext{
* This is the usually accepted meaning of the term flood plain, namely, that it is the work of a constructive river which is silting up its valley, or certain portions of it, during inundations. Gilbert uses the term in a very different sense. He says in Geology of the Henry Mountains, p. 132:

"* * flood-plains are usually produced by lateral corrasion. There are instances, especially near the seacoast, of river plains which have originated by the silting up of valleys, and have been afterward partially destroyed by the same rivers when some change of level permitted them to
} 
same law. It is true the curvature is faint, so faint that in the field it may be imperceptible to the eye, and in diagrams most authors ignore it, and represent the cross-section of a flood-plain by a straight line; but the curve, though slight, is real. If compared with the débris fan of a mountain torrent it would be found to correspond to the outer margin, where it blends into the plain and the convexity is slight. Strictly speaking, a flood-plain extending many miles along a river cannot be likened to a single alluvial cone; it is a composite structure made up of a multitude of overlapping cones, each having its apex upstream at that point where the silt composing it left the channel. The overlaps obscure the convexity of individual cones, and the net result is a curve of large radius and low convexity.

Cross-section of constructive River.-The typical cross-section of a river having a flood plain - a constructive river - so far from showing a straight line from the channel to the bluffs, presents a convex curve of deposition, besides a number of other distinct elements. If no terraces are present the section will be as in figure 10, each half of the valley presenting a

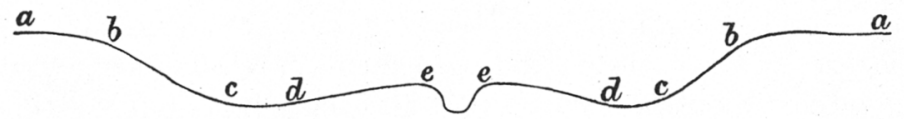

Figure 10.-Cross-section of a constructive River.

$a b=$ Weather cúrve at crest of bluffs ; $b c=$ Water curve of erosion; $c d=$ Swamp; $d e=$ Water curve of deposition.

weather curve, two water curves of opposite character, and a swamp along the line of intersection of the water curves. The presence of terraces adds much complexity. The swamp at $c d$ is caused by a depressed surface and an impervious subsoil. Only the finest argillaceous sediments spread so far from the channel or from the bluffs, and these

cut their channels deeper; and these instances, conspiring with the fact that the surfaces of flood plains are alluvial, and with the fact that many terraces in glacial regions are carved from unconsolidated drift, have led some American geologists into the error of supposing that river terraces in general are records of sedimentation, when in fact they record the stages of progressive corrasion."

The question about the true significance of terraces is aside from the present discussion, but the ordinary meaning of flood-plain is too well settled to disturb it by so radical a departure as that here proposed. Since Gilbert himself admits it to be descriptive of a real phenomenon, we might conclude that there are two kinds, flood-plains of corrasion and flood-plains of sedimentafion, and that all we need is to distinguish these and use the term in each case withits proper adjunct; but a closer analysis reveals two difficulties. In the first place, since the products of corrasion on one side of a stream are deposited as sediments on the other side, it turns out that the plain of cor. rasion, or planation, is also a plain of sedimentation. This difficulty tends to merge the two kinds into one; but there is an opposite and more radical difficulty which rends them apart. The plain of planation is not properly a flood-plain at all. Lateral corrasion is not exclusively a flood phenomenon, though it is active in floods. The plain of planation differs so much from true flood deposits that the term flood plain.ought to be restricted to the latter, as is usually done. 
form a gumbo,* which imparts the impervious quality to the subsoil, and at the same time their small bulk and relatively slow growth occasions a line of depression. Even when well drained, this part of the river bottom is apt to be cold and sour until redeemed by tillage and the admixture of silicious elements.

True Form of Cross-section.-The old definition of the upper course of a river postulates a $V$-shaped cross-section. This is not strictly true, even of fresh ravines at the headwaters. The sides are water curves of erosion, and they conform to the general law that the slope varies inversely as the quantity of water flowing upon it. Since the bottom of a slope receives the water from above as well as its own quota of the rainfall, its pitch must always be less steep than that above if it is a true water curve. One side of a ravine may be a talus with its sharp structural angle and uniform declivity, the corrasion at its base proceeding so rapidly as to give no time for a water curve to form. Very rarely, when the bottom only of a ravine is undergoing erosion, a talus slope may exist on both sides, and the section will then be accurately V-shaped; but if the corrasion at the base of either wall lags or stops, the wash of that slope will speedily convert it into a concave water curve of erosion. The actual result is usually composite, including elements or remnants of a structural angle, modified by a water curve. At all events, it is a curve rather than an angle, and a $\mathrm{V}$ with curved sides quickly passes into a $U$. The middle course of a river is usually said to have a U-shaped valley, but in fact this form belongs to all parts of a river, the only difference being the breadth of the U. It is in the upper course alone that it has anything like normal proportions. In the middle, and especially in the lower course, it sprawls out and flattens down until all resemblance to the fifth vowel is lost. Moreover, the presence of terraces and water curves of deposition so complicates the cross-section that the comparison of it with any letter of the alphabet is no longer useful.

Cross-section of River having no Flood-plain.-The most important real distinction between the different parts of a river valley is the presence or absence of a flood-plain. If this is present the section will be as in figure 10 ; if it is absent, it will be as in figure 11, in which, as compared with figure 10, the middle portion, including the flood-plain with its convex curvature, has been cut out.

The is a wide range of variation among different rivers in that portion of the valley which has a cross-section like figure 11. It may be very narrowly U-shaped, or it may open out to such breadth as to become anomalous. Under ordinary climatic and geologie conditions the

* Gumbo is a peculiar, tenacious, fine-grained clay. The use and meaning of this term in the western states is so well established, that it promises to become a useful and expressive word. 
narrow U-form would include the whole course of the river above the initial flood plain.

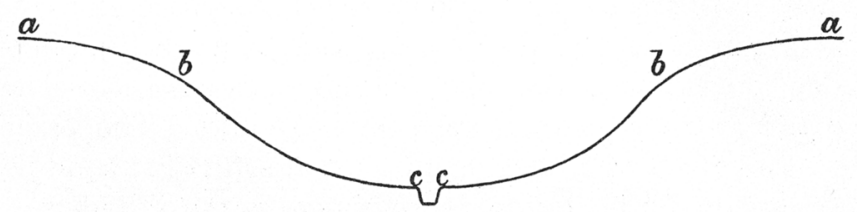

Figure 11.-Cross-seclion of a river Valley having no Flood-plain.

Each half of the valley has only two elements, the weather curve $a b$ and the water curve $b c$.

Anomalous Valleys of the great Plains.-But certain peculiar conditions sometimes intervene to prevent the development of a flood plain where it normally belongs. Then we have the anomaly of a valley some miles in breadth without a flood-plain, which is so diametrically opposed to our ordinary conceptions of rivers that we are at once impelled to seek its explanation. It is upon the great plains at the eastern base of the Rocky mountains that we find the most striking examples of wide valleys without flood-plains. The lower part of the water curve ( $m n$, figure 12)

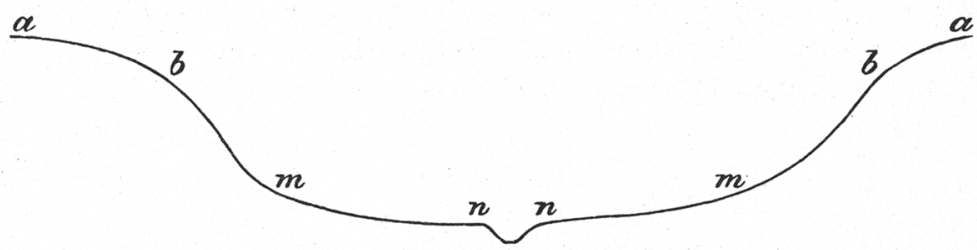

Figure 12.-Cross-section of a broad Valley of the Plains having no Flood-plain.

$a b=$ weather curve; $b m n=$ water curve, of which the lower portion, $m n$, is greatly extended.

may be a mile or two in breadth. At the point $m$ the valley wall begins to be well defined. The valley floor $m m$ is also well defined, but quite remarkable for its wide departure from horizontality. The point $m$ may be fifty feet above $n$. It is unmistakably a valley floor, but its steepness is astonishing and perplexing. Moreover, the anomaly does not stop with the unusual form of the cross-section. The quality of the land contradicts all expectations which would naturally be entertained respecting river bottoms. Instead of a uniform stretch of rich alluvium we find irregular alternations of loam, sand, gravel, gumbo and alkali patches. The best element, the loam, may indeed predominate, and hence the valley may support a prosperous agriculture; but the valley lands of the plains are generally inferior to the table lands, thus reversing the conditions which usually prevail.

The plains are built up of incoherent masses of sand, gravel, clay 
and marl, in which the rainfall is absorbed and reaches the rivers by slow percolation, instead of flowing quickly and copiously on the surface; hence, if there are any floods at all, they are infrequent and irregular. Without regular floods there can be no distinct flood-plain, the silt deposited during the rare overflows being obscured and subordinated to the heterogeneous wash from the hills. The patchy character of the soil arises from local conditions affecting the wind drifts and washings from the bluffs, bringing down here gravel, yonder sand, and again the mingled silicious, calcareous and argillaceous elements constituting loam. Alkaline carbonates and sulphates are developed in low, undrained spots, where water lies and evaporates. By the meanderings of the channel the valley floor is plowed up and redeposited, but this process tends to still greater differences rather than greater uniformity. The assorting action of the currents segregates the coarser and finer elements and deposits each by itself. The absence of floods intensifies and perpetuates these diversities. No general blanket of rich silt is spread in annual layers to cover and blend into one the heterogeneous soils, nor do the copious waters spread over the alkali patches to dilute and wash out their bitterness. Thus arise these anomalous, wide valleys without flood-plains, in which the whole valley floor from the bluffs to the channel on either side slopes sharply inward, and the soils are patchy and wholly unlike ordinary bottom lands.

\section{SUMmary.}

This paper makes no pretensions to an exhaustive treatment of the elements of land sculpture. There are other forces at work, and the forces named operate in ways not herein discussed in detail ; but in the broad, general view of the subject the face of nature is moulded chiefly by these forces: (1) Upheaval, which furnishes the structural blocks to be chiseled into pleasing forms ; (2) Weathering, which rounds off the asperities and covers the land with graceful, swelling curves; (3) Washing of water, which yields concave flowing lines upon slopes of erosion, and low convex curves of deposition.

The combination of the weather curve with the water curve of erosion is here noted and explained for the first time. It constitutes the greatest charm of natural landscapes, and its effects are universal. 